\title{
Augmentation of DC-Link Protection System of PMSG Based Wind Turbine Using Fuzzy Logic Controlled Buck Controller System
}

\author{
Md. Zubairul Haque, Md. Rifat Hazari, Mohammad Abdul Mannan and Junji Tamura
}

\begin{abstract}
Recently, permanent magnet synchronous generator (PMSG) is one of the most familiar type of generator for wind power plant (WPP). Generally, PMSG is connected to grid using back to back converter. During fault period, power imbalance situation can be happened between machine side and grid converter. Thus, the DClink voltage can be rise significantly which can damage the whole converter system. In this paper, a novel DCLink protection system based on fuzzy logic controlled buck converter is designed in order to augment the transient stability of the PMSG system. The new buck converter along with its control system is designed to manage the supplied voltage of the braking resistor during fault period. For investigating the performance of the proposed system, fault analysis is performed on different scenarios in PSCAD/EMTDC software.
\end{abstract}

Keywords: PMSG, power system stability, fuzzy logic controller, buck converter, DC-Link protection.

\section{Introduction}

Coal, oil and gas used in conventional power plants emits greenhouse gases. Global warming is becoming a serious problem for the world due to the use of fossil fuel-based power plant [1]. Moreover, fossil fuels are being depleted gradually. That is why exploring alternative fuel sources is becoming essential. Clean and renewable energies are being searched to get rid of conventional power plant's drawbacks. Many countries have been planning WPPs, because of economic competition [2]. In recent times, PMSG is becoming so much popular for wind turbine instead of doubly fed and squirrel cage induction generators. PMSG has reduced flux linkage because of having large air gaps [3-4]. Full rating power electronics converters of PMSG increases its fault ride through (FRT) potential at the time of network disturbance.

Md. Zubairul Haque is a master's student of EEE department of American International University-Bangladesh, Dhaka-1229, Bangladesh. Email: marine614@gmail.com

Md. Rifat Hazari is an Assistant Professor of the Department of EEE, American International University-Bangladesh, 408/1, Kuratoli, Khilkhet, Dhaka-1229, Bangladesh. Email: rifat@aiub.edu Mohammad Abdul Mannan is a Professor and Director of the Department of EEE, American International University-Bangladesh, 408/1, Kuratoli, Khilkhet, Dhaka-1229, Bangladesh. Email: mdmannan@aiub.edu

Junji Tamura is a Professor at EEE Dept. of Kitami Institute Technology, 165 Keon-cho, Kitami, Hokkaido, 090-8507, Japan. Email: tamuraj@mail.kitami-it.ac.jp
According to FRT code, during network disturbance, the PMSG should stay connected with the power system and should support similar like conventional units. To ensure effective FRT capability, DC-Link protection controller should be incorporated in PMSG system. Additionally, the power converter can be damaged due to excessive DC-Link voltage during fault condition which is expensive to replace.

A rapid voltage drop appears at the wind generator terminal, if there occurs any fault in the grid side. After that active power supplied to the grid is minimized. As a result, generator keep continuing to generate the active power, because the stator side converter (SSC) of PMSG is not coupled with AC grid system. So that voltage rises in the DC-Link circuit because of unbalance energy between the grid side converter (GSC) and the SSC. In conventional way, the active power produced by PMSG is dissipated by inserting a DC chopper circuit with a breaking resistor into the DC-Link circuit for maintaining the active power stability in the DC-Link circuit [3, 5-6]. But conventional strategies cannot control the dissipating power in a more efficient way.

The fuzzy logic controller (FLC) based buck converter in the DC-Link circuit of PMSG can resolve the above-mentioned problem. The FLC have the capability to provide variable gain during network disturbance which ensures effective power dissipation across the braking resistor.

Therefore, the key contribution of this paper is to design a new FLC based buck converter for DC-Link protection of PMSG. The new strategy will augment the transient stability of the PMSG system. The usefulness of the new strategy is tested through simulation analysis on a simple grid system consists of PMSG. The overall system performance of the proposed DC-Link protection is compared with the conventional DC-Link control strategy.

\section{PMSG based Wind Turbine Model}

The overall block diagram of the PMSG system is presented in Fig. 1. The rotor of the generator is made of permanent magnets and the stator is attached to an AC grid system via AC/DC/AC converter. The SSC converts the AC power comes from the PMSG to DC power. This SSC is controlled by an SSC controller. The GSC is employed to transform the DC power into AC power and supply to the AC grid system. This GSC converter is controlled by a GSC controller which 


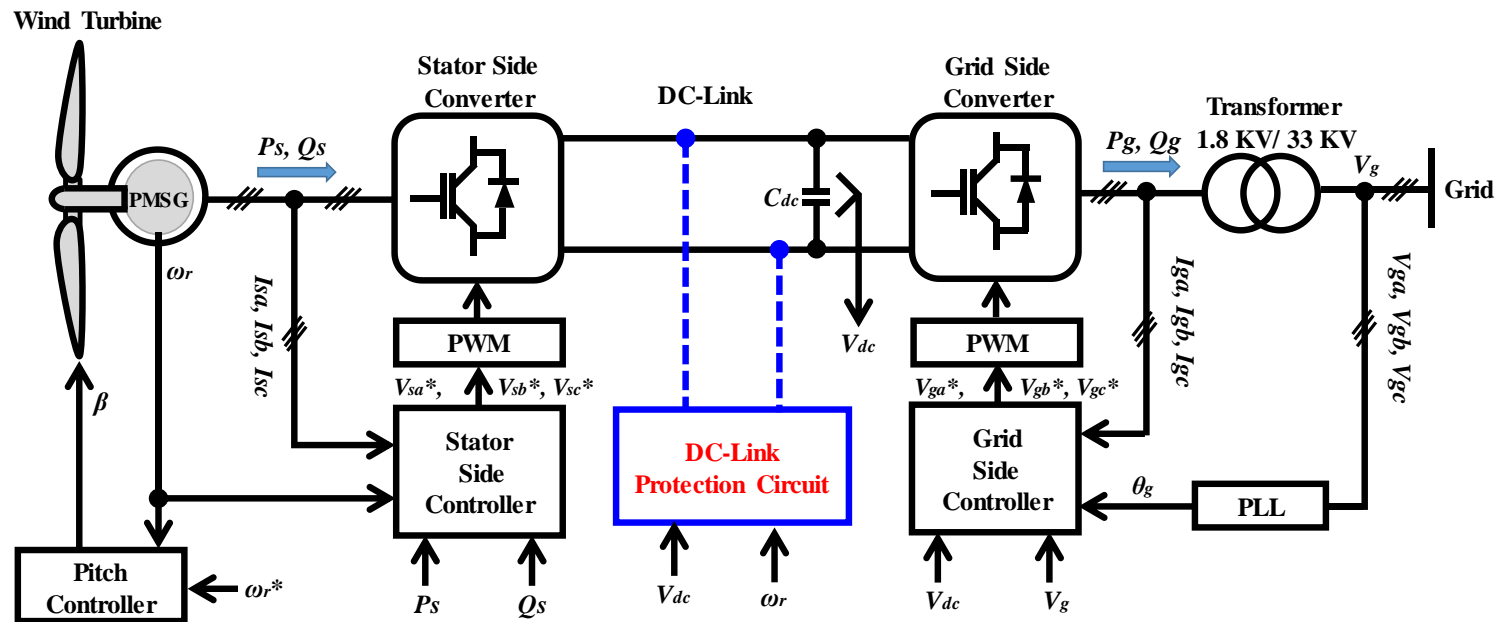

Fig. 1: PMSG system.

adjusts DC-Link voltage across the capacitor and reactive power supplied to the grid system. PMSGbased WPPs allows variable-speed operations, that's why no gear box is required to control the rotor speed. Because of having full scale power converters, this system allows independent active and reactive power control. Also, a protection circuit of DC-Link is fitted in parallel to the DC-Link capacitor. This DC-Link protection will protect the both converter circuit and capacitor due to overvoltage during fault period. IGBTs are used for both converters. Also, the necessary gate pulses for the converters are generated using pulse width modulation (PWM).

\subsection{Aerodynamic Design}

Mechanical power obtained $\left(P_{w}\right)$ from wind can be mathematically defined as follows [7-8]:

$$
P_{w}=0.5 \rho \pi R^{2} V_{w}^{3} C_{p}(\lambda, \beta)
$$

Here, the density of air is denoted by $\rho$, power coefficient is denoted by $C_{p}$, wind speed is denoted by $V_{w}$ and rotor blade radius is denoted by $R$.

The expression $C_{p}$ can be defined as follows [9]:

$$
\begin{aligned}
& C_{p}(\lambda, \beta)=c_{1}\left(\frac{c_{2}}{\lambda_{i}}-c_{3} \beta-c_{4}\right) e^{\frac{-c_{5}}{\lambda_{i}}}+c_{6} \lambda \\
& \frac{1}{\lambda_{i}}=\frac{1}{\lambda-0.08 \beta}-\frac{0.035}{\beta^{3}+1} \\
& \lambda=\frac{\omega_{r} R}{V_{w}}
\end{aligned}
$$

Here, $C_{1}, C_{2}, C_{3}, C_{4}, C_{5}, C_{6}$ are characteristics coefficient [10]. Turbine's rotational speed is denoted by $\omega_{r}$, blade pitch angle is denoted by $\beta$ and tip speed ration is denoted by $\lambda$.

Based on various $\beta$, the $C_{P^{-}} \lambda$ characteristics is presented in Fig. 2. Fig. 2 shows that when $\beta$ is $0^{0}$ then optimum tip speed ratio $\left(\lambda_{\text {opt }}\right)$ is 8.1 and optimum power coefficient $\left(C_{\text {Popt }}\right)$ is 0.48 .

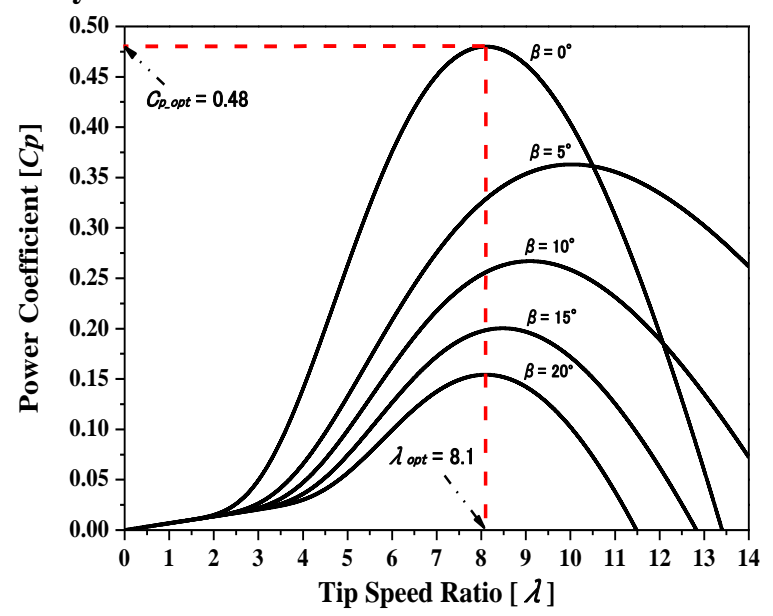

Fig. 2: $C p$ - $\lambda$ characteristic curve for different $\beta$.

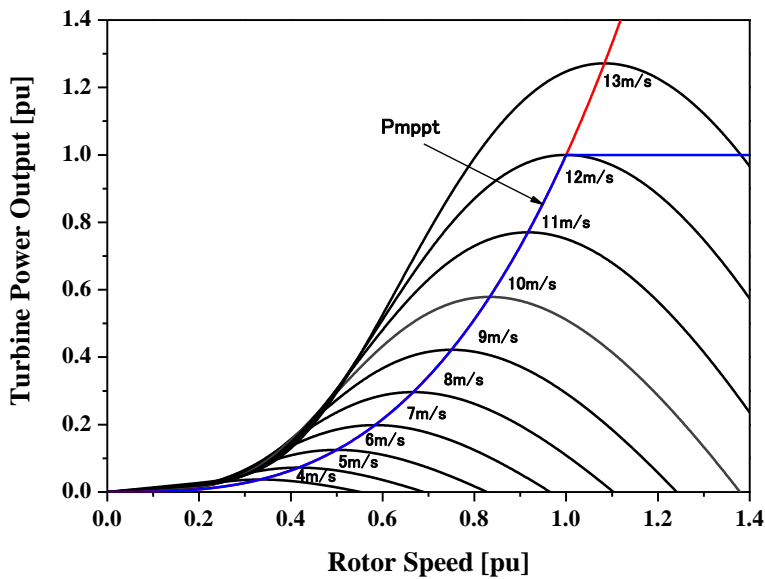

Fig. 3: MPPT curve for PMSG.

In this work, the maximum power point tracking (MPPT) method presented in equation (5) is considered [11]:

$$
P_{M P P T}=0.5 \rho \pi R^{2}\left(\omega_{r} R / \lambda_{\text {opt }}\right)^{3} C_{p_{\_} \text {opt }}
$$

Depending upon the equation, the MPPT curve of PMSG is presented in Fig. 3 . 


\subsection{PMSG Model}

The PMSG model can be expressed using differential equations based on dq axis frame, where the equations are referred to the stator [12]. The equation can be written as follows:

$$
\begin{aligned}
& L_{d s} \frac{d i_{d s}}{d t}=V_{d s}-R_{S} i_{d s}+\omega_{s} i_{q s} L_{q s} \\
& L_{q s} \frac{d i_{q s}}{d t}=V_{q s}-R_{s} i_{q s}+\omega_{s} L_{d s} i_{d s}-\omega_{s} \varphi_{m}
\end{aligned}
$$

Where, inductances of stator winding $=L_{d s}$ and $L_{q s}$, winding resistance of the stator $=R_{s}$, voltages of stator $=V_{d s}$ and $V_{q s}$, stator currents of stator $=I_{d s}$ and $I_{q s}$, angular frequency of stator $=\omega_{s}$, flux linkage of the permanent magnet $=\psi_{m}$.

\subsection{Model of Mechanical Drive Train}

The impact of wind speed fluctuation can be analyzed from the shaft model of single rotating [13]. Two mass shaft model must be used, at the time of analyzing the result of a sudden fault in the power system [14].

It is possible to represent a gear box, generator and the wind turbine rotor as two mass inertia model. Two mass drive train model's state space equations can be written as follows:

$$
\begin{aligned}
& \frac{d}{d t}\left(\delta_{t}-\delta_{g}\right)=\left(\omega_{t}-\omega_{g}\right) \\
& \frac{d \omega_{t}}{d t}=\left(\frac{1}{2 H_{t}}\left(T_{m}-D\left(\omega_{t}-\omega_{g}\right)-K\left(\delta_{t}-\delta_{g}\right)\right)\right. \\
& \frac{d w_{g}}{d_{t}}=\left(\frac{1}{2 H_{g}}\right)\left(D\left(\omega_{t}-\omega_{g}\right)+K\left(\delta_{t}-\delta_{g}\right)-T_{e}\right)
\end{aligned}
$$

Here, $H_{g}$ and $H_{t}=$ moment of inertia of generator and turbine rotor. $\omega_{g}$ and $\omega_{t}=$ wind turbine generator and rotor speed. $T_{m}$ and $T_{e}=$ wind turbine torque and electromagnetic torque. $\delta_{g}$ and $\delta_{t}=$ angular positions of generator and rotor. $D_{\text {shaft }}$ and $K_{\text {shaft }}=$ damping coefficient and spring constant.

\subsection{Pitch Control Mechanism}

A pitch controller system of wind turbine is demonstrated in Fig. 4 [3]. Usually, rotor speed of variable speed wind turbine is regulated not to be over its setting value by the pitch controller.

If the rotor speed of the generator does not exceed setting value $(1 \mathrm{pu})$, the blade pitch angle is set to $0^{\circ}$.

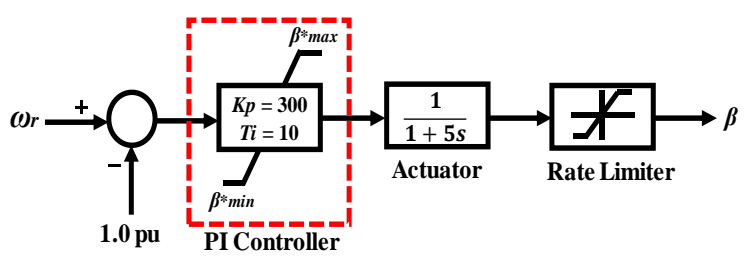

Fig. 4: Pitch control mechanism of PMSG.

\subsection{Converter Control Scheme}

The SSC controller block diagram is depicted in Fig. 5 [10-11]. Active and the reactive power output of the PMSG is controlled through SSC. In the SSC controller, q-axis current $\left(I_{s q}\right)$ controls the active power and d-axis current $\left(I_{s d}\right)$ controls the reactive power. MPPT controller gives active power reference $\left(P_{\text {ref }}\right)$. Unity power factor activity is confirmed by taking zero reactive power reference $\left(Q_{s} *\right)$.

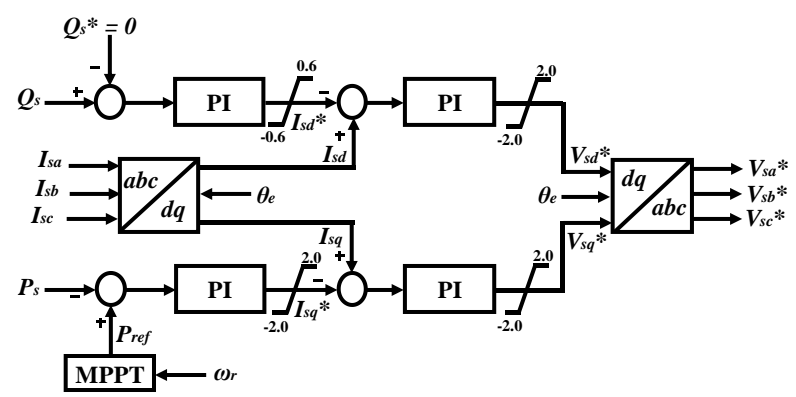

Fig. 5: SSC control system.

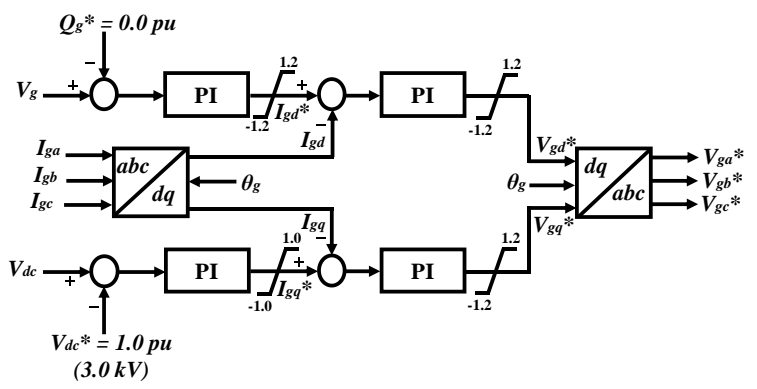

Fig. 6: GSC control system.

Fig. 6 depicts the GSC controller block diagram [1011]. GSC controller has two cascade loops. GSC output $\mathrm{d}$-axis and q-axis currents $\left(I_{g d}\right.$ and $\left.I_{g q}\right)$ are controlled by the GSC controller for managing the reactive power of GSC along with DC-Link voltage. The reference DCvoltage is established to $3.0 \mathrm{kV}$ and reactive power reference $\left(Q_{g}{ }^{*}\right)$ is set to zero.

\section{Proposed Protection System of DC- Link Circuit}

The GSC output power of the PMSG decreases during network disturbance. Thus, excess voltage appears in DC-Link circuit of the power converters of PMSG. When a fault occurs, voltage between the SSC and GSC increases suddenly due to the energy imbalance. If a breaking resistor is inserted in the DCLink circuit, it can control the voltage expansion by dissipating the surplus energy across a power electronic switch as described in Ref. [3, 5, 10]. However, using conventional methods $[3,5,10]$, energy of SSC and GSC can be still imbalance because of uncontrolled dissipated energy of braking resistor. This unbalanced energy appears because of the imbalance between the breaking resistor's power capacity and the generators output power.

Therefore, to avoid the problems of conventional strategy, in this paper, a novel DC-Link protection 
system based on FLC is proposed, which is shown in Fig. 7. The main switch along with buck converter make the overall protection system. When the voltage of DC-Link circuit goes above 1.05 pu because of any network disturbance, main switch activates the DCLink protection.

According to the power generated by PMSG $(P)$, buck converter controls the DC voltage $\left(V_{d c}\right)$ of the breaking resistor $\left(R_{r c}\right)$. MPPT controller determines the PMSG output from its rotational speed. By using this information, PMSG stability can be increased by balancing the produced power of PMSG and received power of breaking resistor.

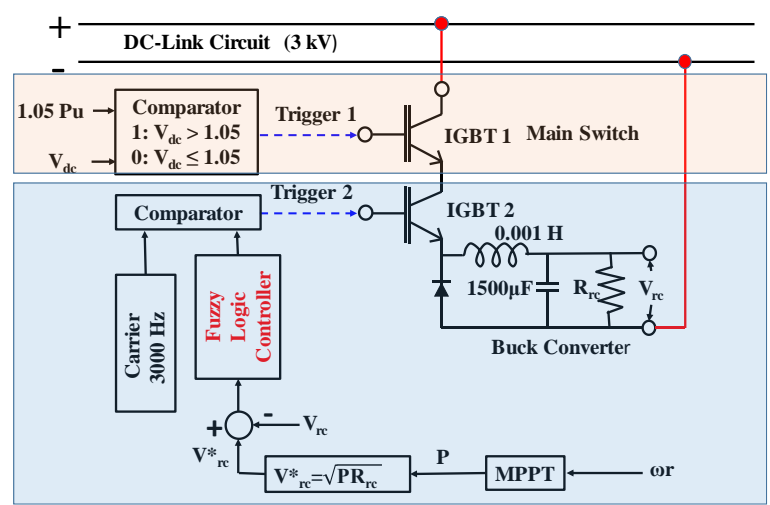

Fig. 7: Proposed DC-Link protection system.

The buck-chopper's basic principle as a switch breaker is shown in Fig. 8 [15].

The chopper becomes on during the period $T_{o n}$ and during this period source voltage and load $\left(R_{r c}\right)$ are connected. During $T_{\text {off }}$ period current $i_{0}$ of $R_{r c}$ flows to communication diode $\left(D_{F}\right)$ and $V_{r c}$ goes to zero. The following equation shows the average DC voltage of the load.

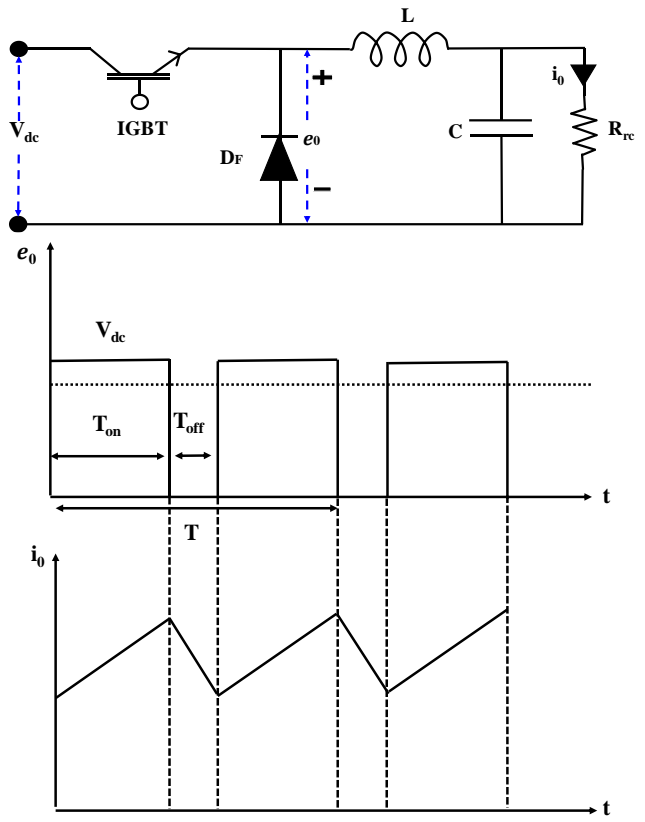

Fig. 8: Buck converter system.

$$
\begin{aligned}
& e_{0}=V_{d c^{\alpha}} \\
& \propto=D=\left(\frac{T_{o n}}{T_{o n}-T_{o f f}}\right)=\frac{T_{o n}}{T}=f . T_{o n}
\end{aligned}
$$

Where, $e_{0}$ : DC voltage on load, $\alpha, D$ : duty cycle, $f$ : frequency, $T$ : period.

There occurs a voltage dip in grid side voltage at the time of network disturbance. That's why power supplied from the converter is influenced. Once the network fault is eliminated, voltage of converter gets back to the normal condition and active power will be feed to power system.

Additionally, the grid parameters are changed during fault condition than that of steady-steady condition. During fault period, protection system controller must provide variable gain in order to enhance the transient stability of the PMSG. To guarantee the above-mentioned concern, a FLC is used to regulate the buck converter. The detail design technique of the proposed FLC will be described in the next section.

\section{Design of Fuzzy Logic Controller}

A block diagram of proposed FLC is shown in Fig. 9. A membership function, fuzzification, a rule base, a fuzzy interface and defuzzification make the FLC as shown in Fig. 10 [16].

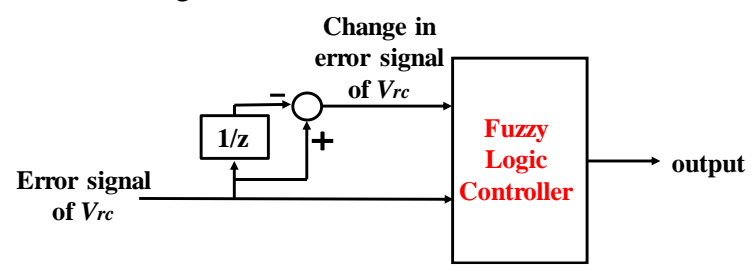

Fig. 9: Proposed FLC.

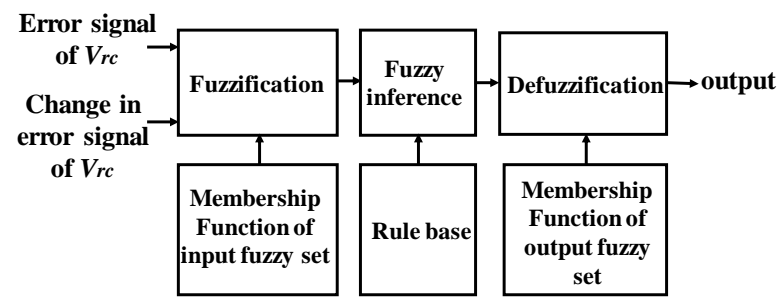

Fig. 10: Inside structure of FLC.

The error and change in error signal of $V_{r c}$ is taken as input of the FLC and the output will be compared with high frequency carrier wave in order to generate the gate driving signal.

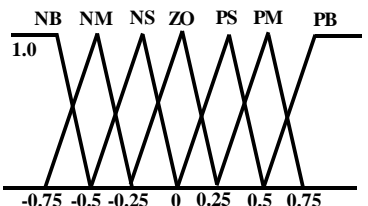

(a) inputs

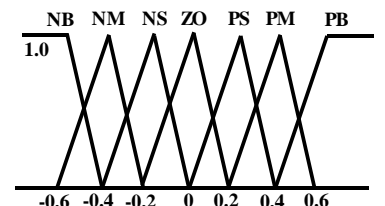

(b) output
Fig. 11: Membership functions.

The input and output fuzzy sets of the proposed controller are designed using triangular membership functions (MFs) which is shown in Fig. 11. In Fig. 11, linguistic variables are zero (ZO), negative small (NS), negative big (NB), negative medium (NM), positive medium (PM), positive big (PB) and positive small 
(PS). The MFs are designed using trial and error basis to get the best result.

Table 1 shows the complete rules which is used in this study.

Table 1: Rules of FLC.

\begin{tabular}{|c|c|c|c|c|c|c|c|c|}
\hline \multicolumn{2}{|c|}{ output } & \multicolumn{7}{|c|}{ change in error signal of $V_{r c}$} \\
\hline & & $P B$ & $P M$ & $P S$ & $Z O$ & $N S$ & $N M$ & $N B$ \\
\hline \multirow{7}{*}{$\begin{array}{l}\text { error } \\
\text { signal } \\
\text { of } V_{r c}\end{array}$} & $P B$ & PB & PB & $\mathrm{PB}$ & PM & PM & PS & $\mathrm{ZO}$ \\
\hline & $P M$ & PB & PB & PM & PM & PS & $\mathrm{ZO}$ & NS \\
\hline & $P S$ & $\mathrm{~PB}$ & $\mathrm{PM}$ & PM & PS & $\mathrm{ZO}$ & NS & $\mathrm{NM}$ \\
\hline & $Z O$ & PM & $\mathrm{PM}$ & PS & $\mathrm{ZO}$ & $\mathrm{NS}$ & $\mathrm{NM}$ & $\mathrm{NM}$ \\
\hline & $N S$ & PM & PS & $\mathrm{ZO}$ & NS & NM & NM & NB \\
\hline & $N M$ & PS & $\mathrm{ZO}$ & NS & NM & NM & $\mathrm{NB}$ & NB \\
\hline & $N B$ & $\mathrm{ZO}$ & NS & $\overline{\mathrm{NM}}$ & NM & NB & NB & NB \\
\hline
\end{tabular}

Defuzzification in accomplished by center of gravity method [16].

\section{Model of Power System}

Fig. 12 depicts the power system configuration, which is designed to verify the ability of the proposed protection system of DC-Link. In this model, a $20 \mathrm{MW}$ PMSG-based wind turbine is attached to an infinite bus power grid with a dual transmission line and two transformers. The frequency of the grid is $50 \mathrm{~Hz}$ and 20 MVA is considered as the base. Table 2 presented the parameters of PMSG.

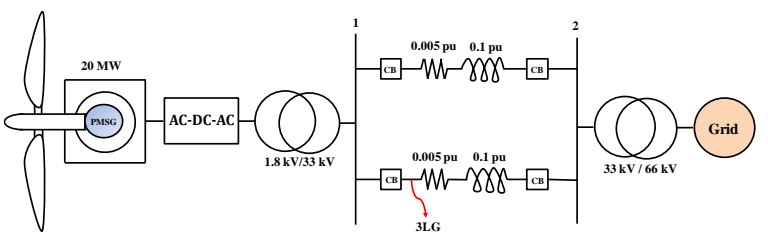

Fig. 12: Model of power system.

\begin{tabular}{|c|c|}
\hline MVA & 20 \\
\hline$R_{s}$ & $0.01 \mathrm{pu}$ \\
\hline$L_{s}$ & $0.1 \mathrm{pu}$ \\
\hline$X_{d}$ & $0.9 \mathrm{pu}$ \\
\hline$X_{q}$ & $0.7 \mathrm{pu}$ \\
\hline Flux & $1.4 \mathrm{pu}$ \\
\hline$H_{t}$ & $5.2 \mathrm{~s}$ \\
\hline$H_{g}$ & $0.8 \mathrm{~s}$ \\
\hline$D$ & 1.5 \\
\hline$K$ & 296 \\
\hline
\end{tabular}

Table 2: Parameters of PMSG.

VI. Simulation Results and Case Study Simulation analysis is achieved by PSCAD/EMTDC software on a model system presented in Fig. 12. Three line to ground (3LG) fault adjacent to bus 1 is taken as acute network disturbance. The network disturbance applied at $0.1 \mathrm{~s}$ with a time span is $0.1 \mathrm{~s}$. The faulty transmission line is opened at $0.2 \mathrm{~s}$ and reclosed again at $1.0 \mathrm{~s}$ by using the circuit breakers (CBs). The wind speed put in to PMSG is remained constant at $12 \mathrm{~m} / \mathrm{s}$.

The proposed DC-Link protection control system's effectiveness is confirmed by considering three scenarios. In scenario 1 , there is no protection system involved in the DC-link circuit. In scenario 2, conventional DC-link protection is used for the protection of DC-link circuit $[3,5,10]$, and in scenario 3, proposed fuzzy logic-based DC-Link protection system is considered for the protection of DC-link circuit.

Fig. 13 presents the profile of DC-Link voltage of PMSG. The graph clearly indicates that the DC-Link voltage can be perfectly regulated in Scenario 3 (proposed case) compared to Scenarios 1 and 2. This is because, the dissipating power across the breaking resistor is now controlled using proposed FLC-based buck converter system in the DC-Link protection.

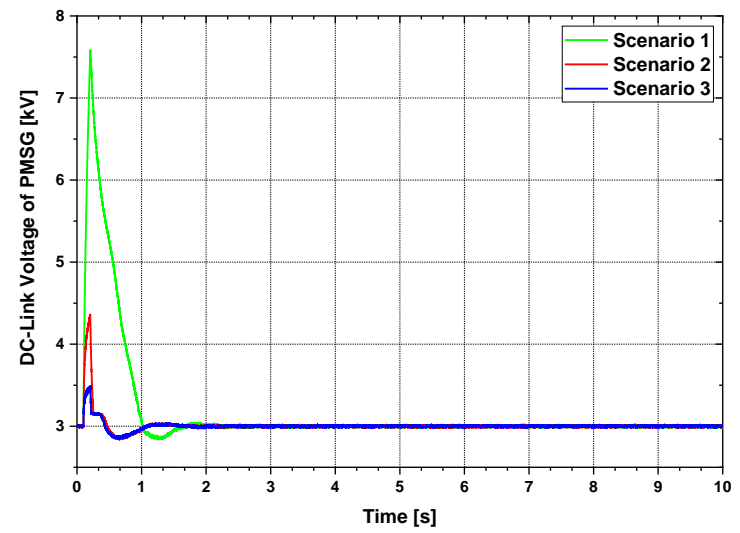

Fig. 13: DC-Link voltage response of PMSG.

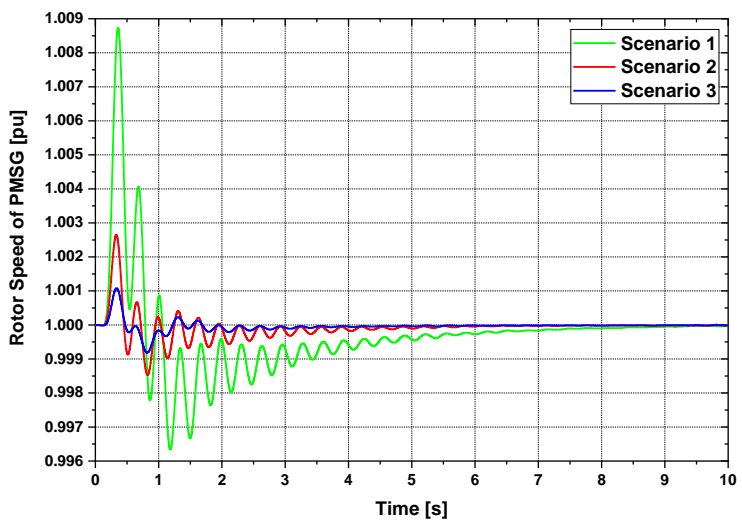

Fig. 14: Rotor speed response of PMSG.

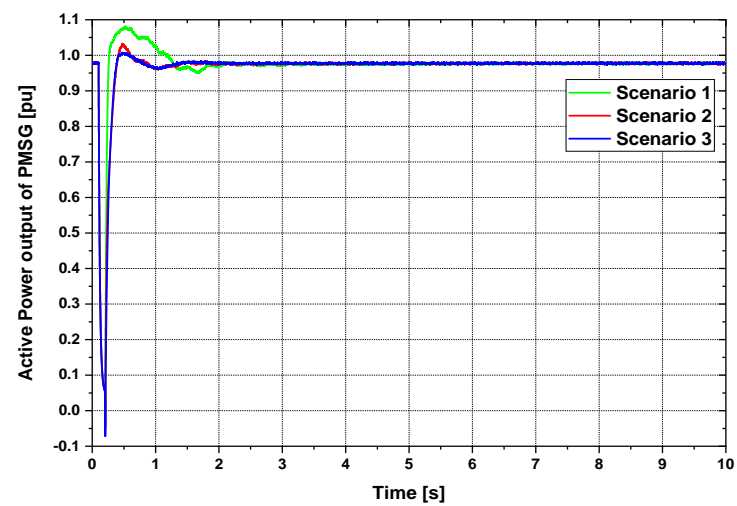

Fig. 15: Active power response of PMSG. 


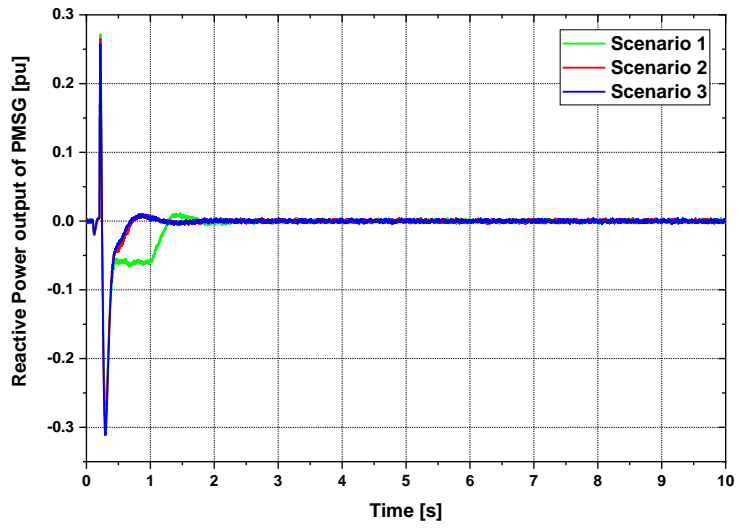

Fig. 16: Reactive power response of PMSG.

The profile of rotor speed of PMSG is depicted in Fig. 14. From the figure, the rotor speed of PMSG is more stable and less fluctuating in Scenario 3 compared to Scenarios 1 and 2 after the network disturbance.

Finally, the profile of active and reactive power of PMSG are illustrated in Figs. 15 and 16. The power swing and variation are smaller in Scenario 3 then other Scenarios.

From the above analysis and discussions, the proposed FLC controlled buck converter-based DCLink protection system can improve the transient stability of PMSG-based wind turbine.

\section{Conclusion}

In this paper, a new fuzzy logic-based DC-link protection system is proposed to enhance the PMSG's transient stability. Different scenarios are presented to substantiate the suitability of the proposed system. To verify that, severe network disturbance, i.e. $3 \mathrm{LG}$, is considered. Simulation results indicate that proposed protection system based of FLC can manage well the DC-link voltage and other parameters of PMSG i.e. rotor speed, active and reactive power output.

As a future work, the proposed protection system of DC-Link can be employed to doubly fed induction generator (DFIG) system.

\section{References}

[1] A. H. M. S. Ula, "Global warming and electric power generation: What is the connection?," in IEEE Transactions on Energy Conversion, vol. 6, no. 4, pp. 599-604, Dec. 1991. [2] Global status report 2017 [Online]. Available: https://www.worldgbc.org/sites/default/files/UNEP\%20188_ GABC_en\%20\%28web\%29.pdf [Accessed: 25 November 2019].

[3] M. R. Hazari, M. A. Mannan, A. Umemura, R. Takahashi, J. Tamura, "Stabilization of Wind Farm by Using PMSG Based Wind Generator Taking Grid Codes into Consideration," Journal of Power and Energy Engineering, Vol. 6, No. 11, pp. 40-52, 2018.

[4] G. Michalke, A. D. Hansen, T. Hartkopf, "Control strategy of a variable speed wind turbine with multipole permanent magnet synchronous generator," Proc. of European Wind Energy Conference and Exhibition, Milan, Italy, 7-10 May 2007.

[5] M. R. Hazari, A. Umemura, R. Takahashi, J. Tamura and M. A. Mannan, "A new fuzzy logic based control strategy for variable speed wind generator to enhance the transient stability of fixed speed wind generator," 2017 IEEE Manchester PowerTech, Manchester, 2017, pp. 1-6.

[6] S. M. Muyeen, R. Takahashi, T. Murata and J. Tamura, "A Variable Speed Wind Turbine Control Strategy to Meet Wind Farm Grid Code Requirements," IEEE Transactions on Power Systems, vol. 25, no. 1, pp. 331-340, 2010.

[7] M. R. Hazari, E. Jahan, M. A. Mannan, and J. Tamura, "Coordinated Control Scheme of Battery Storage System to Augment LVRT Capability of SCIG-Based Wind Turbines and Frequency Regulation of Hybrid Power System," Electronics, vol. 9, no. 2, p. 239, Feb. 2020

[8] M. R. Hazari, M. Mannan, S. Muyeen, A. Umemura, R. Takahashi, and J. Tamura, "Stability Augmentation of a GridConnected Wind Farm by Fuzzy-Logic-Controlled DFIGBased Wind Turbines," Applied Sciences, vol. 8, no. 1, p. 20, Dec. 2017

[9] S. M. Muyeen, J. Tamura and T. Murata, Stability augmentation of a grid connected wind firm, London, Springer-Verlag, 2009.

[10] M. Rosyadi, A. Umemura, R. Takahashi, J. Tamura, N. Uchiyama and K. Ide, "Simplified model of variable speed wind turbine generator for dynamic simulation analysis," IEEJ Transactions on Power and Energy, Vol. 135, No. 9, pp. 538-549, 2015.

[11] M. R. Hazari, "Stability Enhancement of GridConnected Wind Farm and Hybrid Power System by Variable Speed Wind Generators," Ph.D. Thesis, Kitami Institute of Technology, Japan, 2019.

[12] A.G. Sanchez, M.G. Molina, A.M. Rizzato Lede, "Dynamic model of wind energy conversion systems with PMSG-based variable-speed wind turbines for power system studies," International Journal of Hydrogen Energy, Vol. 37, No. 13, pp. 10064-10069, 2012.

[13] N. W. Miller, J. J. Sanchez-Gasca, W. W. Price and R. W. Delmerico, "Dynamic modeling of GE 1.5 and 3.6 MW wind turbine-generators for stability simulations," 2003 IEEE Power Engineering Society General Meeting (IEEE Cat. No.03CH37491), Toronto, Ont., 2003, pp. 1977-1983 Vol. 3. [14] P. M. Anderson, Subsynchronos Resonance in Power System, 1994, New York: IEEE Pres.

[15] N. Mohan, T. M. Undeland, and W. P. Robbins, Power Electronics Converters, Applications and Design, 2003, Hoboken, NJ: John Wiley \& Sons.

[16] B. K. Bose, Modern power electronics and AC drives, Prentice Hall PTR.

Md. Zubairul Haque received his B.Sc. Engg. Degree in

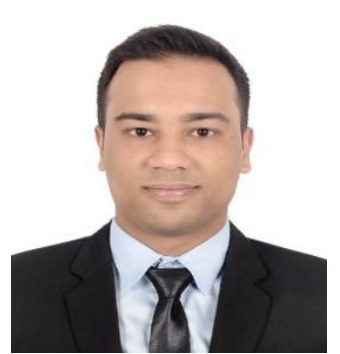
Electrical and Electronic Engineering from American International UniversityBangladesh (AIUB) in February 2016. Currently he is completing his M.Sc. Engg. Degree in Electrical and Electronic Engineering from American International UniversityBangladesh (AIUB). He worked as an Assistant Engineer in the Design \& Costing department at Paradise cables Ltd and currently he is working as an Assistant Engineer in the Research \& Development department at Dynasty Food \& Beverage Industry. His research interests are renewable energy systems, DC-link protection system of PMSG under network disturbance. 
Md. Rifat Hazari received his B.Sc. Engg. and M.Sc. Engg.

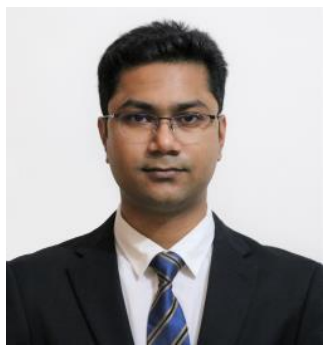

Degrees in Electrical and Electronic Engineering from American International University-Bangladesh (AIUB) in August 2013 and December 2014, respectively and Ph.D. Degree in Energy Engineering from Kitami Institute of Technology (KIT), Japan, in March 2019. He served as a Lecturer in Electrical and Electronic Engineering department at AIUB. Currently, he is working as an Assistant Professor in the Electrical and Electronic Engineering department at AIUB. He received the MINT (Academic Excellence) Award 2017 from KIT for the outstanding research of 2017 academic year, Best Paper Award in the Australasian Universities Power Engineering Conference 2017, Melbourne, Victoria, Australia and Best Presentation Award in the IEEJ Branch Convention 2017, Hakodate, Japan. His research interests are renewable energy systems (especially wind power \& photovoltaic power systems), power system stability and control, microgrid and hybrid power systems, HVDC system, analysis and control of rotating electrical machines.

Mohammadad Abdul Mannan was born in Laxmipur,

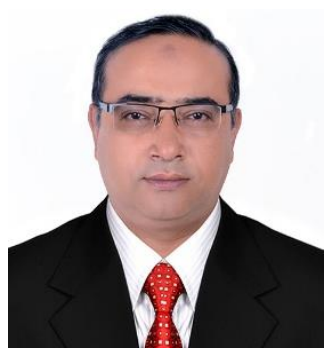
Bangladesh on January 01, 1975. He received his B. Sc. Eng. Degree from Rajshahi University of Engineering and Technology (RUET former BITR), Bangladesh, in 1998, and Masters of Eng. and Dr. of Eng. degrees from Kitami Institute of Technology, Japan, in 2003 and 2006 respectively, all in electrical engineering. He then joined in the American International University Bangladesh (AIUB) as an Assistant professor in May 2006. He served in AIUB as an Associate Professor from December 2013 to November 2016. Now he is working as a Professor and Director of Faculty of Engineering in AIUB. His research interests include electric motor drive, power electronics, power system, wind generation system and control of electric motor, power electronic converters, power system, and wind generation system. Prof. Dr. Mannan is a member of the IEB and IEEE.

Junji Tamura received his B. Sc. Eng. Degree from Muroran

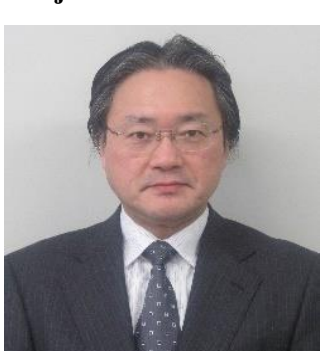
Institute of Technology, Japan, in 1979, and M.Sc. Eng. and Dr. Eng. degrees from Hokkaido University, Japan, in 1981 and 1984 respectively, all in electrical engineering. He became a lecturer in 1984, an Associate Professor in 1986, and a Professor in 1996 at the Kitami Institute of Technology, Japan. Prof. Dr. Tamura is a Senior Member of the IEEE Power Engineering Society. 
BLANK 